This is the author accepted manuscript of the article published ahead-of-print (April 14, 2020) in Journal of Documentation. The final published version at: https://doi.org/10.1108/JD-01-2020-0010

This AAM version is under the CC BY-NC Licence 4.0. ㄷ 2020, Emerald Publishing Limited

\title{
Manifestations of expert power in gatekeeping: a conceptual study
}

\section{Reijo Savolainen}

Faculty of Information Technology and Communication Sciences

Tampere University, Finland

(to be published in Journal of Documentation, vol. 76, 2020)

\begin{abstract}
Purpose - To elaborate the picture of the relationships between information and power by examining how expert power appears in the characterizations of gatekeeping presented in the research literature. Design/methodology/approach - Conceptual analysis examining how expert power is constitutive of the construct of gatekeeper, and how people subject to the influence of gatekeeping trust or challenge the expert power attributed to gatekeepers. The study draws on the analysis of 40 key studies on the above issues.
\end{abstract}

Findings - Researchers have mainly constructed the gatekeepers' expert power in terms of superior knowledge and skills applicable a specific domain, coupled with an ability to control or facilitate access to information. The gatekeeper's expert power has been approached as a contextual factor that facilitates rather than controls access to information. The power relationships between the gatekeepers and those subject to gatekeeping vary contextually, depending the extent to which the latter have access to alternative sources of information. The findings highlight the need to elaborate the construct of gatekeeping by rethinking its relevance in the networked information environments where the traditional picture of gatekeepers controlling access to information sources is eroding.

Research limitations/implications - As the study focuses on how expert power figures in gatekeeping, no attention is devoted to the role of social power of other types, for example, reward power and referent power.

Originality/value - The study pioneers by providing an in-depth analysis of the nature of expert power as a constituent of gatekeeping.

Keywords Expert power, Gatekeeping, Information seeking, Information Sharing, Power

Paper type: Conceptual paper

\section{Introduction}

In studies on human information behaviour (HIB), researchers have seldom examined how powerrelated factors affect the ways in which people seek and share information. Rare examples of conceptual studies explicitly focusing on this topic include the keynote address delivered by Lucas Introna at the $2^{\text {nd }}$ International Conference on Research in Information Needs, Seeking and Use in Different Contexts (ISIC). Introna (1999) emphasized that power is a factor with great potential to explain the complexities of information behaviour; he strongly called for further research on the relationships between information, people and power. Unfortunately, this call has not received much attention among researchers; HIB studies explicitly concentrating on the issues of information and power can be counted on the fingers of one hand (Mutsheva, 2007; 2010; Olsson, 2007; Heizmann and Olsson, 2015; Olsson and Heizmann, 2015). Seen from a broader perspective, however, the situation is better because HIB research offers a rich body of literature which is relevant to the examination of the relationships between information and power. Many of these studies have focused on the issues of cognitive authority (e.g., Wilson, 1983; Rieh, 2002; Hirvonen et al., 2019) and 
gatekeeping (e.g., Barzailai-Nahon, 2008; Ojennus, 2020). So far, however, the question of how power figures in cognitive authority and gatekeeping has not been addressed in sufficient depth.

The study at hand was preceded by a companion article where the present author (source anonymized, 2019) demonstrated that the construct of cognitive authority can be elaborated further by examining how informational power and expert power manifest themselves in the characterizations of authoritative information sources and how such sources are trusted or challenged among information seekers. The present investigation concentrates on similar issues dealing with gatekeeping. In general, gatekeeping deals with processes through which the access to information sources is being controlled, or through which information content is being filtered before it is disseminated in the media or shared with a group of people (Barzilai-Nahon, 2009). Gatekeeping were chosen for analysis for two main reasons. First, it is assumed that the issues of gatekeeping are highly relevant for the study of the relationships between information and power because gatekeeping is essentially based on an asymmetric relationship between those controlling access to information or filtering information and those subject to gatekeeping. On the other hand, power figures in the ways in which the latter group of people trust or challenge the gatekeepers. Second, even though the studies on gatekeeping have seldom thematized the issues of power per se, these investigations offer a sufficiently rich body of literature characterizing gatekeepers as power holders and the ways in which people are influenced by such actors.

To examine how power figures in gatekeeping, the present study makes use of the concept of expert power originally proposed by French and Raven (1959). More specifically, the main goal of the present study is to elaborate the picture of the relationships between information and power by examining how expert power manifests itself in the characterizations of gatekeeping. To this end, a conceptual analysis was made by concentrating on a sample of 40 key studies characterizing gatekeeping as an instance of power use. The findings contribute to the elaboration of the contextual features of information behaviour, deepening our understanding of the ways in which power as a contextual factor affects information seeking and sharing.

The rest of the article is structured as follows. First, to provide background, the concepts of power, expert power and gatekeeping are introduced, followed by the specification of the conceptual framework, research questions and methodological setting. The main part of the article will be devoted to the report of the findings. The article ends with the discussion of the main findings and reflection of their significance.

\section{Background}

\section{Approaches to power}

Power is a pervasive phenomenon in society; yet there is little consensus on what power fundamentally is and how it should be approached (Clegg, 1989; Foucault, 1998; Haugaard and Clegg, 2009; Lukes, 1974). One of the most widely cited general level definition of power can be found in Max Weber's classic book Economy and Society; power (Macht) is "the probability that one actor within a social relationship will be in a position to carry out his own will despite resistance, regardless of the basis on which this probability rests" (Weber, 1978, p. 53). An alternative view to power is advocated by Michel Foucault. He challenges the idea that power is wielded by certain people or groups by means of domination or coercion. Instead, power is approached as a phenomenon that is dispersed and pervasive in nature. Foucault (1998, p. 63) asserts that "power is everywhere" and "comes from everywhere"; it neither an agency nor a structure. Instead it is a kind of "regime of truth" that pervades society, and which is in constant flux and negotiation. There is no power relation without the correlative constitution of a field of knowledge, nor any knowledge that does not presuppose and constitute at the same time power relations. Thus, power structures discourse, a way of talking about the world, in a discontinuous and diffused manner (Introna, 1999, p. 5). On the other 
hand, Foucault (1991, p. 194) contends that power is not just a negative, coercive or repressive thing that forces us to do things against our wishes, but can also be a necessary, productive and positive force in society. This is because power produces reality, domains of objects and rituals of truth.

The above characterizations are helpful for the understanding of power as a fundamental factor shaping human behaviour and the constitution of society. In empirical studies drawing on social constructionist ideas about information practices, the Foucauldian approach to power has been particularly popular (e.g., Heizmann and Olsson, 2015; Olsson, 2007; Olsson and Heizmann, 2007). One of the strengths of the Foucauldian approach is that it offers a holistic view on the ways in which power relationships are articulated and negotiated in discourse. As the present investigation concentrates on a specific form of social power and does not specifically thematize it as a discursive phenomenon, another research approach was preferred. More specifically, the issues of social power related to gatekeeping will be examined by making use of the classic taxonomy of social power proposed by French and Raven (1959). The taxonomy is well established in studies on social influence. According to Cummings $(2017$, p. 7), the social power base model offered by French and Raven (1959) is the most comprehensive and universally studied power base model to date. The model has been widely used in diverse fields such as social psychology and management science (Elias, 2008; Raven, 2008).

French and Raven (1959) suggested that social influence is based on the power relationships between individuals. More specifically, they departed from the assumption that social influence manifests itself in a change in the belief, attitude, or behaviour of person B (the target of influence), and that such changes result from the action of another person A (an influencing agent). In interaction between person $\mathrm{A}$ and person $\mathrm{B}, \mathrm{A}$ 's control over $\mathrm{B}$ is positively related to diverse sources of power. They are, respectively, based on B's perception that A has the ability to mediate rewards for B in case of B's compliance, B's perception that A has the ability to mediate punishments for B if B fails to conform to A's demand, B's perception that A has a legitimate right to prescribe behaviour for B, B's perception that A has some special expertise, and B's identification with A (French and Raven, 1959, p. 156). Social power is defined as the potential for such influence, the ability of the agent or power figure to bring about such change, using resources available to him or her (Raven, 2008, p. 1).

Drawing on the above assumptions, French and Raven (1959) identified five main types of social power. Legitimate power is formal authority delegated to the holder of a position in an organization. Referent power is based on the charisma and interpersonal skills of the power holder; power of this kind manifests itself in an individual's ability to attract others and build loyalty. Reward power depends on the ability of the power wielder to give others valued material rewards such as benefits and promotions. Coercive power is based on the application of negative influences, including the ability to demote or withhold rewards. Finally, expert power derives from an individual's skills or expertise and the organization's needs for those skills and expertise.

Unlike other sources of power, expert power is usually highly specific and limited to the particular area in which the expert is trained and qualified. When individuals such as these have knowledge and skills that enable them to understand a situation, suggest solutions, and use solid judgment, then people tend to trust them and respect what they say. As subject matter experts, their ideas will have more value, and others will look to them for leadership in that area. This means that ultimately, expert power is based on the perceived credibility of person A. Person B trusts the expert power attributed to person A when B thinks, "I don't really understand exactly why, but A really knows this topic so A must be right." (Erchul and Raven, 1997, p. 139). As the above example suggests, the expert power can originate from the target's (B) belief that the recommendation by the agent (A) is the best thing to do; person B is relying on his or her faith in the superior knowledge of person A. 


\section{Gatekeeping}

Gatekeeping is a ubiquitous and multi-faceted phenomenon which is ultimately based on a power holder's ability to control and/or facilitate other people's access to information (Barzilai-Nahon, 2009; Shoemaker and Vos, 2009). In terms of French and Raven's (1959) typology discussed above, person A acting as a gatekeeper may wield one or more types of social power. He or she may use legitimate power to regulate access to information resources of certain types. The gatekeeper may also use referent power to strengthen the cohesion of an ethnic group characterized by mutual trust and loyalty. Similarly, he or she may make use of reward power by selectively sharing strategically important information to certain individuals within a company, for example. While sharing such information, the gatekeeper may also wield coercive power by intentionally leaving out people who are considered as his or her rivals within the company. Finally, the gatekeeper's ability to control and/or facilitate access to information can be based on his or her expert power, that is, superior knowledge and skills valuable to other people. As an example of gatekeepers with domain-specific expert knowledge, medical professionals monopolize the right of access to prescription drugs, thus assuring their place as gatekeepers (Corra and Willer, 2002, pp. 180-183). On the other hand, the phenomena of gatekeeping also include the issues of how an individual subject to gatekeeping - in terms of French and Raven (1959) - person B accepts or challenges the forms of social power wielded by the gatekeeper (person A). As specified later on, the present study elaborates the nature of expert power inherent in gatekeeping from this viewpoint, too.

The concept of gatekeeping was coined by Kurt Lewin (1943) to describe a wife's role as the person who decides which food ends up on the family's dinner table. By this example, Lewin conceptualized gatekeepers as people who filter in things desired (including information) and filter out things undesired in accordance with certain criteria. Later on, Lewin (1951, p. 187) suggested that that the idea of gatekeeping could be applied more generally: "not only for food channels but also for the traveling of a news item through certain communication channels in a group, for movement of goods, and the social locomotion of individuals in many organizations". To achieve this, Lewin applied the idea of gatekeeping to interpersonal and mass communication by conducting experiments regarding group decisions. Lewin (1951) assumed that movement within the communication channel and between the channel and its external environment is controlled by one or more gatekeepers. Gatekeeper was defined as the person who chooses what should pass through each gate offering access to a communication channel. Using Lewin's metaphor, gates are kept by individuals who hold strategic social power (for example, a housewife for buying food) and who thereby influence their cultural and social environment (Jucquois-Delpierre, 2007, p. 246).

Since Lewin's use of the gatekeeper concept, it has become embedded in various fields of scholarship, including political science (e.g., Soroka, 2012), sociology (e.g. Corra and Willer, 2002), information science (e.g., Barzilai-Nahon, 2008), and management (e.g., Schultze and Boland, 2000). With these developments, however, the picture of gatekeeping has become fragmented, encompassing different models and theories conceptualizing diverse aspects of this phenomenon. The picture of gatekeeping has also been complicated due to the fact that gatekeepers are not always individuals; for example, departments within organizations can function as gatekeepers (Haas, 2015, p. 1036). Gatekeepers can also be non-human mechanisms such as electronic gateways and search engines because they filter access to information. Moreover, the exact characterization of gatekeepers has been rendered more difficult because they may also act in the roles of opinion leader, knowledge broker and organizational boundary spanner (Agada, 1999; Haas, 2015). For example, MetoyerDuran (1993, p. 112) defined gatekeepers as those "who influence opinions, disseminate information, or facilitate cultural adaptation in many different settings". This suggests that gatekeepers also serve as opinion leaders, that is, individuals who influence the views of less socially and politically active people by virtue of the trust they inspire (Katz and Lazarsfeld, 1955). 
There are also differences in the ways in which gatekeepers are characterized in diverse fields of study (Barzilai-Nahon, 2008). Management scientists mainly refer to gatekeepers as intermediaries breaking walls or crossing boundaries in order to connect and facilitate access to information (Allen, 1977; Schultze and Boland, 2000) or "key individuals who are both strongly connected to internal colleagues and strongly linked to external domains" (Tushman and Katz, 1980, p. 1071). Information scientists treat gatekeepers as those who guard and preserve a community's information or who function as agents to gather and disseminate information (Metoyer-Duran, 1993; Sturges, 2001). For example, Agada (1999) characterized "inner-city" gatekeepers as information intermediaries who move between cultures, linking their community members with alternatives or solutions. To compare, most of the literature in communication studies treats the gatekeeper as a selector of news items. This aspect was emphasized in White's (1950) classic study where he characterized "Mr. Gates", a pseudonymous newspaper editor whose decisions were so subjective that he rejected one-third of incoming news items because of his personal feelings about the content.

Two decades later, Donohue, Tichenor, and Olien (1972, p. 43) provided a broader definition of gatekeeping as all processes involved in information control, including the processes of withholding, transmission, shaping, manipulation, display, repetition, and timing. Nevertheless, this approach is closely linked to the original gatekeeping concept, as it focuses on a linear process of information transmission. Similarly, Shoemaker (1991, pp. 1-2) emphasized the aspect of the selection process because gatekeeping deals with the process by which the "billions of messages that are available in the world are winnowed down and transformed into the hundreds of messages that reach a given person on a given day". As Shoemaker and Vos $(2009$, p. 3) put it, the most obvious effect of gatekeeping of this kind on the media audience is cognitive, that is "shaping the audience's thoughts about what the world is like. Information that gets through all gates can become part of people's social reality, whereas information that stops at a gate generally does not". In recent characterizations of the gatekeeping phenomena, increasing attention has been paid to social and technological factors that transform the gatekeeping practices and change the relationships between gatekeepers and those subject to gatekeeping, for example, consumers. One of the main issues deal with individualized patterns of news consumption. There are many gates, but audiences tend to attend a relatively small percentage of those gates (Vos, 2015, p. 10). Heinderyckx (2015) identified two factors predicting that gatekeeping theory will continue to be relevant in networked and social media environments. First, it is assumed that a "brand" replaces the older medium as the audience point of contact, but familiar gatekeeping processes continue to exist behind the scenes. Second, it is possible that the audience's limited attention span limits the impact of the unconstrained space and content of the network.

The concept of gatekeeping has been approached somewhat differently in studies on technological gatekeepers (Yoo and Park, 2018, p. 62). The concept of technological gatekeeper originally proposed by Allen (1966) - was mainly inspired by Katz and Lazarsfeld's (1955) study of opinion leaders. Later on Allen (1977, p. 145) elaborated the construct of technological gatekeeper referred to as "a small number of key people to whom others frequently turned for information. These key people differ from their colleagues in the degree to which they expose themselves to sources of technological information outside their organisation". Such gatekeepers sought and maintained broad-ranging and long-term relationships with colleagues beyond their organizations and exchanged more information with colleagues with whom they had developed friendships. From this perspective, gatekeeping was seen as a two-step process where the technological gatekeeper first accessed external information and then distributed it to R\&D group members. Unlike Katz and Lazarsfeld (1955), however, Allen allowed gatekeepers to be more than formally designated opinion leaders and emphasized the role of informal gatekeepers (Barzilai-Nahon, 2009). Later on, technological gatekeepers have also been referred to as individuals adopting the role of boundary spanners, in which they engage in processes that filter and channel information into their respective organizations (Katz and Tushman, 1979). 
More recently, Barzilai-Nahon (2008) proposed the Network Gatekeeping Theory (NGT). It specifies the key components of gatekeeping: gate (the passage point); gatekeeping (the process); gatekeeper (who performs gatekeeping); the gated (on whom gatekeeping is exercised); and gatekeeping mechanisms (the means used to carry out gatekeeping). In NGT, gate is defined as entrance to or exit from a network or its sections, while gatekeeping is referred to as the process of controlling information as it moves through a gate. Gatekeeping is constituted by a number of activities, ranging from selection, addition, withholding and display to channelling, integration, disregard, and deletion of information. NGT thus suggests that the study of gatekeeping should not be confined to the processes of choice, distribution, and intermediation of information; rather, NGT advocates a more comprehensive concept of information control, as it is affected by the network.

\section{Conceptual framework and research questions}

To examine the nature of power inherent in gatekeeping, the present study makes use of the typology of social power (French and Raven, 1959) reviewed above. However, to strengthen the focus of the study, the investigation concentrates on the manifestations of expert power, while the ways in which legitimate, coercive, referent and reward powers figure in gatekeeping will be excluded from the analysis. It is evident that the study of the types of social power such as these would require a separate study.

Following the ideas of French and Raven (1959), expert power was generally defined as an asymmetric relationship between person $\mathrm{A}$, that is, the gatekeeper controlling and/or facilitating access to information and person B, that is, information seeker or receiver on whom gatekeeping is exercised. The study was focused on expert power because it is evident that superior knowledge and skills owned by gatekeepers mainly affect the ways in which they control and/or facilitate access to information, as well as filter information before it is disseminated to others. In the above context, expert power also occupies a major role from the perspective of the information seeker or receiver (person B). It is assumed that his or her ways to trust or challenge the gatekeeper as controller or facilitator of access to information is influenced by how the information seeker or receiver perceives the expertise attributed to the gatekeeper.

To examine how expert power figures in gatekeeping, conceptual analysis was conducted by focusing on two aspects. First, an attempt was made to find out how expert power manifests itself in the characterizations of gatekeepers. Second, it was examined how power of this kind would manifest itself in the characterizations of how the gatekeepers are trusted or challenged. To examine the above issues in greater depth, the present study addresses the following research questions.

- RQ1. In which ways have researchers characterized the gatekeepers as holders of expert power?

- RQ2. How have researchers characterized the ways in which those subject to the influence of gatekeepers trust or challenge them as holders of expert power?

\section{Research material and analysis}

The research material was identified by conducting searches in seven major databases: Ebsco Ultimate, Google Scholar, LISA, Sage, Science Direct, Scopus and Springer Link. The search terms included gatekeeping, gatekeeper, power, social power, and expert power. In addition, combinations of search terms were used, for example, gatekeeping AND power, and gatekeeping AND information seeking. The searches resulted in the identification of 86 potentially relevant studies published within the period of $1943-2020$. The preliminary analysis revealed that many of these investigations are less relevant for the present study because they devote marginal attention to power-related issues of 
gatekeeping. After having excluded investigations of this kind, altogether 40 studies directly relevant for the present study were included in the final sample. Most of the studies are journal articles and book chapters. These investigations were selected by two criteria. First, the studies characterized gatekeepers as actors qualified by knowledge, skills and expertise valuable to other people, thus indicating an asymmetric relationship between the gatekeeper and those on whom gatekeeping is exercised. Second, these studies explicated how people approach gatekeepers by trusting or challenging them.

The research material consisting of 40 key studies was scrutinized by means of conceptual analysis (Furner, 2004). First, to obtain on overview, the above studies were read carefully. The material was then coded by the present author for the conceptual analysis. This method treats the components of the study objects as classes of objects, events, properties, or relationships. More precisely, the analysis involves defining the meaning of a concept and its attributes by inductively identifying and specifying the contexts in which it is classified under the concept in question. To conduct the conceptual analysis, relevant text portions (paragraphs and sentences) characterizing the main object of the study, i.e., gatekeeping was identified. The text portions were equipped with codes indicating how the characterizations of gatekeeping and gatekeepers are descriptive of expert power. Similarly, codes were assigned to text portions indicative of gatekeepers are trusted or challenged among information seekers and receivers.

More specifically, following Furner's (2004) terminology, attributes indicative of gatekeepers as holders of expert power were identified from the coded material. Attributes of this kind included the type of the gatekeeper, e.g., technological gatekeeper (Allen, 1977) and ethnolinguistic gatekeeper (Metoyer-Duran, 1991), and the specific knowledge and skills owned by the gatekeeper, for example, active reader-consumers of professional engineering and scientific journals (Allen, 1977). Moreover, attributes indicating how gatekeepers are trusted or challenged among information seekers and receivers included degree of being controlled, e.g., "threatening gated" and "vagabond reader" (Barzilai-Nahon, 2008). The coding was rendered difficult in that the characterizations of expert power were sometimes intertwined with those typical to referent power wielded by ethnolinguistic gatekeepers, for example. In this case, the focus was placed on the characterizations indicative of expert power, while the aspect of referent power was excluded from the analysis. Finally and most importantly, the conceptual analysis was conducted by scrutinizing the similarities and differences between diverse characterizations depicting how expert power manifests itself in gatekeeping. If needed, the research material was revisited by checking details in order to ensure that there are no anomalies.

\section{Findings}

\section{Gatekeepers as holders of expert power}

Gatekeepers are often characterized as actors "with power" (Barzilai-Nahon, 2008, p. 1495). The manifestations of power attributed to gatekeepers tend to vary in in diverse domains of human action. In workplace discourses, for example, the manifestation of power typically takes the form of an appeal to institutional norms and standard practices (Holmes, 2007, pp. 2011-2012). Power may also manifest itself benevolently and persuasively through mentor-managers, concerned not only with the goals of their organisations, but also with the welfare of their staff.

Despite differences such as these, common to most characterizations of gatekeepers is the identification of two gatekeeping roles: (i) the gatekeeper that controls access to information, and acts in an inhibitor capacity by limiting access to or restricting the scope of information; and (ii) the gatekeeper that acts as innovator, change agent, communication channel, link, intermediary, helper, adapter, opinion leader, broker, and facilitator (Laidlaw, 2010, p. 254). In the former sense, the "gatekeeping power" manifests itself in the monitoring of boundaries (Holmes, 2007, pp. 2011-2012), 
while the latter aspect of gatekeeping mainly deals with persuasion power. In terms of the conceptual framework depicted above, the gatekeeper as power holder (person A or an institution) controls or facilitates the extent to which person B - on whom the gatekeeping is exercised - can have access to information.

The features of gatekeepers as holders of expert power have been approached somewhat differently in studies on gatekeeping. For example, Petruzzelli (2008) characterized knowledge gatekeepers as actors having a great capability to collect, combine, and diffuse knowledge. Studies on domain or context-specific gatekeepers have resulted in the identification of actors such as ethnolinguistic gatekeepers (Metoyer-Duran, 1991) and inner-city gatekeepers (Agada, 1999). Metoyer-Duran (1991; 1993) found that ethnolinguistic gatekeepers are knowledgeable about information access and enthusiastic about using information technologies to facilitate their gatekeeping role. She developed a taxonomic model of ethnolinguistic gatekeepers that considered cognitive and affective domains in addition to concept and data usage dimensions. The model specified a variety of ethnolinguistic gatekeeper types such as impeders, brokers, information professionals, and leader-executives (Metoyer-Duran, 1991).

More recently, Lu (2007, pp. 110-113) proposed the category of culturally certified information gatekeeper. Different conventions, customs, and cultural norms have traditionally legitimated some people as having the authority in transmitting certain information. For instance, in some societies, a mother is usually the gatekeeper in transferring cooking secrets of the family. Such individuals become gatekeepers not mainly by virtue of their expertise in a domain or possession of information resources. Moreover, there may be nominated information gatekeepers. Within an inner circle of peers, they tend to be more knowledgeable, well acquainted with information resources on certain subjects, and willing to interact with their peers to discuss things. Over time, these individuals, due to their expertise and active involvement in the current events or problems, are "nominated" as information gatekeepers in a group or community. The above examples suggest that expert power attributed to gatekeepers is shaped by a variety of social and cultural factors. In a mass communication context, psychological pressures on gatekeepers such as newspaper editors to pass a news item through the gate or not can affect the gatekeeper's "likes and dislikes ... ways of thinking about a problem, preferred decision-making strategies, and values" (Shoemaker, 1991, p. 75). Factors of this kind can influence the ways in which gatekeepers can wield their expert power while making decisions to reject, select, and shape messages.

The nature of expert power has been specified in more detail in the characterizations of technological gatekeepers. The concept of a technological gatekeeper was initially developed to aid an understanding of an emergent and informal role occupied by those few employees in research and development departments who acquired external knowledge on scientific developments and who acted as boundary spanners between external and internal environments when translating knowledge so that it could be disseminated to appropriate colleagues in the firm (Walsh, 2015, p. 394). For example, Allen (1977, p. 145) defined technological gatekeepers as "a small number of key people to whom others frequently turned for information". These key people differ from their colleagues in the degree to which they expose themselves to sources of technological information outside their organisation. More specifically, Allen (1977) characterized technological gatekeepers as active reader-consumers of the literature, especially professional engineering and scientific journals, thus suggesting that they systematically accrue their knowledge stock on which their expert power is based.

More recently, in an empirical study on examining the work of competitive intelligence (CI) analysts working in a US manufacturing firm Schultze and Boland (2000, pp. 206-207) elaborated the traditional picture of gatekeeper's role as a selective disseminator of information. The expert power of CI analysts is mainly based on the acquisition of strategically important knowledge. As strategic advisors they continuously scan the external business environment for news that decision-makers in the company needed to know. The analysts prided themselves in their business 
knowledge relevant to the organization and about the effective use of this information. They thus claimed to know what constituted "the right person", "the right information", "the right format" and the "right time" in selective dissemination of information. Moreover, to emphasize their positions as experts, the dissemination of information was guided by three questions: "who needs to know?", "who wants to know?" and "who should know?" One indication of the expert power owned by the gatekeepers is that the analysts contrasted their logic of selective and situation-specific information dissemination, which they characterized as "targeting" the information, different from the "blasting and splattering of information" that they believed the corporate librarians to engaged in.

Interestingly, by claiming to know what the "right information" and who the "right person" was, the CI analysts attributed to themselves a certain degree of omniscience. Their belief in their superior knowledge of effective organizational informing practices was evident in their claims that the CI analysts ought to be recognized as the "information czars" who "owned" "the entire knowledge management process. As legitimate gatekeepers, they saw it as their responsibility to maintain these information privileges and to control the dissemination of information. Moreover, their personal accumulation of unique knowledge and expertise that related specifically to US Company and its industry differentiated them from other knowledge workers in that it enabled them to pre-empt questions, guide inquiry and foster strategic thinking among the decision makers in US Company's business units (Schultze and Boland, 2000, pp. 208-210). Thus, from the viewpoint of the gatekeeper, he or she would have the responsibility to select the people who needed to know, wanted to know and ought to know about important information and events.

All in all, the above characterizations suggest that the gatekeeper's expert power is based on his or her privileged intermediary function: a gatekeeper links people to something "outside". Being "outside" broadly refers to things unfamiliar or unknown - out of the immediate reference of an individual. A gatekeeper controls a strategic portion of a channel, and through filtering, links people to something "outside" - whether that channel or thing "outside" is for information, goods, news, or people (Lu, 2007, p. 108). On the other hand, gatekeepers are not necessarily neutral agents in the flow of information because they reinterpret information for their communities, thus unavoidably putting their own "biasing effect" on mediated messages by either reinforcing or counteracting the messages they relay (Hirokawa and Lowe, 2002, p. 9).

The biasing effect is exemplified by the findings of an empirical investigation on immigrant Mexican-American and Korean teen-aged children acting as information mediators for their non-English-speaking parents and other family members (Chu, 1999). As gatekeepers, the children mediated information about a wide variety of issues such as medical services, banking, jobs, transportation, home repairs and entertainment. However, the children did not always impart all the information they obtained to their parents. The selective mediation of information was due to their decision that their parents did not need to know everything, and it was easier that way. More generally, if immigrant children have a good grasp of the language spoken in their new country, they may not only become gatekeepers due to their superior language skills but also in many cases their families' primary information source (Fisher et al., 2004). On the other hand, this means that the immigrant parents are forced to play the role of the gated if they delegate the information seeking responsibilities to their children.

Many of the above characterizations of gatekeepers as holders of expert power are historically connected to the pre-Internet era, that is, the period of time before which the Internet was being widely used in society. At that time, for example, newspaper editors as domain-specific experts made choices and audiences simply lived quietly with those choices (Heinderyckx and Vos, 2016, p. 30). However, when digital networks superseded centralized wired networks, it became possible to communicate with millions of users at little or no cost (Bastos et al., 2013, p. 261). The gatekeeper's traditional sender-to-receiver role became increasingly obsolete, as the "gated" persons could also act as information creators and providers. Even information filtered by gatekeepers such as news editors can be later redistributed or changed as it moves through the gateways. For example, Twitter users 
may bypass traditional gatekeepers such as these. Wu and associates (2011) found that although media outlets are very active users on Twitter, only about $15 \%$ of tweets received by ordinary users were received directly from mass media channels. On the other hand, research on Twitter use supports the view that gatekeepers have become increasingly atomized and fragmented, as users receive and pass on information without the mediation of media outlets (Bastos et al., 2013, pp. 268-269).

As gatekeeping in digital networks occurs through a process in which a multitude of users pass information forward, developments such as these have rendered it more difficult to identify individual gatekeepers and find out how their expert power shapes the relationships between the gatekeepers and the gated. However, the above developments do not mean that gatekeeping would no longer be based on the wielding of expert power because lay people can circumvent the professional gatekeepers, thanks to the information resources available in the forums of social media. There are still influential traditional gatekeepers with expert power, for example, medical professionals and lawyers filtering and interpreting information before it is disseminated to information seekers and receivers.

\section{Trusting and challenging gatekeepers as holders of expert power}

Early studies on gatekeeping largely remained silent about the role of the "gated", that is, those whom gatekeeping is being exercised upon (Barzilai-Nahon, 2008, pp. 1494-1495). This is particularly typical to studies in which gatekeeping is approached as a one-way direction and a top-down process (e.g., Shoemaker, 1991). In studies of this kind, traditional news audience is occupied the role of the gated, bounded by the scope of events and perspectives presented in news coverage. The major focus was placed on the role of the gatekeeper as the holder of expert power rather than understanding how the control and filtering of information affect the relations between gatekeepers and gated, and their impact on gated. Similarly, early studies on technological gatekeepers depicted their influence on other people on a general level only. Allen (1977) suggested that technological gatekeepers seek and maintain broad-ranging and long-term relationships with colleagues beyond their organizations and actively exchange information with colleagues with whom they had developed friendships. From this perspective, gatekeeping was seen as a two-step process where the technological gatekeeper firstly accessed external information and secondly distributed it to R\&D group members (Walsh (2015, p. 395). However, as the focus was placed on the role of the gatekeepers, studies such as these did not specify how information shared by gatekeepers was trusted or challenged among its receivers. Traditionally, the gatekeeper was perceived as powerful and the gated as powerless, or at most as having minimal power relative to the gatekeeper (Barzilai-Nahon, 2009, pp. 49-50). Overall, this approach resulted in that the power relationships between the gatekeepers and gated remained an implicit issue.

In contrast, recent approaches such as the Network Gatekeeping Theory (NGT) proposed by Barzilai-Nahon (2008, pp. 1497-1501) offer a broader perspective on the role of the receivers of filtered information. NGT advocates that being a subject to gatekeeping does not necessarily imply that the gated is lacking alternatives or that gatekeeping is forced on her or him. This is because the gated is bounded by gatekeeping sometimes from her or his free will and the expert power of gatekeepers is accepted as a natural state of affairs (Barzilai-Nahon, 2008, p. 1496). Importantly, NGT identifies the gated according to their salience to gatekeepers, that is, the degree to which gatekeepers give priority to competing gated claims. In this regard, four attributes of the gated are particularly important: (i) their political power in relation to the gatekeeper, for example, the ability to achieve political and media goals by boycotting a newspaper to force editors to change editorial decisions, (ii) their information production ability, (iii) their relationship with the gatekeeper, and (iv) their alternatives in the context of gatekeeping.

Most significantly from the perspective of the present study, NGT proposes that the salience of a particular gated to a gatekeeper is correlated with possession of these attributes. As noted 
above, salience refers to the degree to which gatekeepers give priority to competing gated claims. The gated with the "political power," "information production ability" and "alternatives" attributes is described as a "threatening gated" who currently contributes to the community but may switch to other gatekeepers if their needs are not met (Ojennus, 2020, p. 392). This conceptualization suggests that the gated sufficiently empowered by informational resources may contest the gatekeeper's expert power because the gated are less dependent on the information content filtered by the gatekeeper. Most notably, digital technologies allow the gated to produce and broadcast their own messages and to choose various content. In contrast, a gated with only the "alternatives" attribute - described as a "vagabond reader" - is more difficult to characterize in this regard because the gated of this type moves from one networked community to another (Barzilai-Nahon, 2008, pp. 1502-1506; Ojennnus, 2020).

In the context of news reading, the extent to which the gated trust information filtered by the gatekeepers depends on how the readers evaluate the agenda setting of news media, for example. However, this task is demanding because media users may face difficulties in trying to evaluate the objectivity and comprehensibility of a news item (Urban and Schweiger, 2014). In an experimental study Pingree and Stoycheff (2013) differentiated two explanations of agenda-setting effects: agenda cueing (the influence of the mere fact of news coverage) and agenda reasoning (the influence of reasons for problem importance in the content of news stories). It appeared that a key moderator in both processes is gatekeeping trust, or trust in the media to base coverage decisions on problem importance judgments. More specifically, gatekeeping trust is trust that news coverage represents the results of a systematic effort by news workers to prioritize problems (Pingree and Stoycheff, 2013, p. 858-862). Items indicative of gatekeeping trust included "News outlets choose which stories to cover by carefully deciding which issues or problems are the most important in society", and "The top stories in a TV newscast are usually about whatever issues the editors think are the most serious, urgent or widespread in society". It appeared that pure cues (without agenda reasons) were more influential on those with higher gatekeeping trust (Pingree and Stoycheff, 2013, p. 864). In contrast, among those with low gatekeeping trust, agenda-setting effects were strengthened by the inclusion of agenda reasons supporting the cue. This suggests that when the mere presence of coverage is not seen as a valid agenda cue, audience members require substantive information about problem importance that can be used in making their own systematic importance judgments.

More recently, Chakraborty and associates (2019) examined the extent to which the gated trusted the expert power of the gatekeepers in the context of social media use. With the growing popularity of social media, a part of the editorial power of selecting news stories has shifted to the audience who select and share the stories that can reach a large number of consumers. This assumption was confirmed in an empirical study where news stories published on the popular news media site http://nytimes.com (NYTimes) over a period of 8 months were analysed. During this period, the authors gathered stories recommended by NYTimes expert editors, as well as the stories most popularly viewed and shared by the audience over Facebook, Twitter, and email. To validate whether the above-mentioned observations generalize beyond NYTimes stories, Chakraborty and associates (2019) analysed news stories from another popular media site - The Guardian. The analysis revealed considerable differences in the types of stories selected by the audience and expert news editors. For example, "World," "Sports," and "Business" stories were more frequently selected by the experts than the audience. On the other hand, "Opinion" pieces as well as stories on "Fashion," and "Health" were selected by the audience much more frequently than by the experts.

Drawing on Castell`s (1997) ideas of power of identity, Chakraborty and associates (2019, p. 690) concluded that the media organizations, from their implicit goal of shaping public opinion, try to create a legitimizing identity of their audience by actively highlighting the stories which they deem to be important. However, the news media audience can create a resistance identity by taking a different path in consuming stories that are at odds with the media organizations want, thus challenging the news editor's expert power. In light of the above studies it is increasingly evident 
that along with the growing significance of the networked information sources, the power dynamic characteristic of traditional gatekeeping occurring in the mass communication media has undergone remarkable changes. Digital technologies allow the audience to produce and broadcast their own messages, to interact with gatekeepers or circumvent them, and to choose various content.

These developments are also behind the phenomenon of apomediation - a user-centered interpretation of gatekeeping proposed by Eysenbach (2007). Apomediation is a neologism created by combining the Greek word apo which means "away from" or "apart" and mediation (communication through an intermediary). As gatekeeping in the traditional sense means intermediation between the provider and user of information, apomediation in contrast exemplifies disintermediation in which gatekeepers as intermediaries are bypassed and replaced by apomediaries (Eysenbach, 2008). Apomediaries are people such as peers and tools like consumer ratings on Shopping.com or TripAdvisor. Different from traditional intermediaries, apomediaries "stand by" to guide a consumer to high quality information. While traditional intermediaries provide "upstream filtering", apomediaries enable and facilitate "downstream filtering". This is because the networked information sources and services enable consumers to circumvent gatekeepers such as travel agents and health professionals to access pertinent information or services directly, whenever they need it and where they need it (Eysenbach, 2007, p. 162). On the other hand, the apomediated approach challenging the expert power of gatekeepers may not always be better than the intermediated model (Eysenbach, 2007, p. 163). The better informed the recipient is (or perceives to be), the better she knows what information or services she needs, the less likely she will need to be dependent on an intermediary. For example, a long-time patient with a chronic condition (e.g., diabetes) is likely to have greater knowledge and self-expertise to critically appraise information found on the Internet than a fellow patient with an acute illness, and thus will not necessarily need a gatekeeping intermediary such as a physician.

\section{Discussion}

Power is a ubiquitous though an under-researched contextual factor of human information behaviour. Drawing on the ideas of French and Raven (1959), the present study filled gaps in this area by examining how expert power figures in the characterizations of gatekeeping.

The first research question dealt with the ways in which researchers have characterized the gatekeepers as holders of expert power. The findings indicate that overall, power of this type is mainly based on an individual's superior knowledge or skills valuable to others in an organization or societal group. Moreover, the expert power attributed to the gatekeeper is seen to originate from an individual's specific position or task in an organization or societal group; examples of such positions include ethnolinguistic gatekeeper (Metoyer-Duran, 1991), technological gatekeeper (Allen, 1977) and competitive intelligence analyst (Schultze and Boland, 2000). However, the expert power constitutive of the gatekeeper is not always based on the professional credentials. In non-work problem solving situations, the gatekeeper's expert power may originate from other sources such as the command of the English language in cases in which a teen-aged immigrant child has better linguistic skills than their parents (Chu, 1999). The construct of apomediation offers another example of expert power owned by lay people (Eysenbach, 2007). In this case, the expert power is based on a an individual's long-time experiential knowledge about health-related issues, for example. Selfexpertise thus acquired may be used while sharing health-related information in the forums of social media in particular.

All in all, superior knowledge and skills in a specific domain, coupled with a gatekeeper's specific position in a social group or an individual's ability to control access to information, as well as to filter it are the major qualities constitutive of the gatekeeper's expert power. Most of the investigations scrutinized in the present study approach the gatekeeper's expert power as a contextual factor that facilitates rather than controls information sharing. This feature is particularly 
characteristic of ethnolinguistic gatekeepers and apomediaries (Agada, 1999; Eysenbach, 2007; Metoyer-Duran, 1991). Similarly, the studies on technological gatekeepers (Allen, 1977) suggest that they may rather be seen as altruistic individuals facilitating rather than restricting access to information. The aspect of control is emphasized most strongly in studies characterizing gatekeepers as selective disseminators of strategically important business information, as exemplified by the analysis of competitive intelligence analysts within a company (Schultze and Boland, 2000).

The second research question focused on how researchers have characterized the ways in which those subject to the influence of gatekeeper's trust or challenge them as holders of expert power. The findings suggest that overall, people cannot be forced to rely on the gatekeeper's expert power or to make use of piece of advice offered by her. In early studies on gatekeeping, the main focus was placed on the features of the gatekeeper and the gatekeeping mechanisms, while the role of the "gated" remained unspecific or they were approached as mass media audiences quietly consuming news items selected by the editors (Heinderyckx and Vos, 2016, p. 30). Similarly, as the study on competitive intelligence analysts priding themselves as "information czars" indicates, the employees of a company may have no choice but make use of strategically important business information filtered by the gatekeepers because there are no alternative sources of information (Schultze and Boland, (2000). The same applies to the example of immigrant parents dependent on information filtered by their children skilled in the English language (Chu, 1999). On the other hand, gatekeeping trust affects the ways in which information receivers and seekers evaluate information filtered by the gatekeepers (Pingree and Stoycheff, 2013). Trust of this type is a sum of many factors, for example, the judgment about the extent to which gatekeepers are able to select and filter pertinent information content and how the selection criteria are justified.

The Networked Gatekeeping Theory developed by Barzilai-Nahon (2008) offers a novel perspective on the above issues by proposing that the gated may also challenge the expert power owned by the gatekeeper. Depending on the political power owned by the gated, as well as their ability to produce information and circumvent the gatekeepers, those subjected to gatekeeping can change their subordinate role by becoming gatekeepers to others. This is enabled by the networked information resources and services - an emancipatory factor behind apomediation, too (Eysenbach, 2007). Drawing on self-expertise in a particular domain, apomediaries may share health information by circumventing traditional gatekeepers whose expert power is based on professional credentials. Similarly, as demonstrated by Chakraborty et al. (2019), media users drawing on resistance identity may challenge the news editor's expert power by preferring media content that is valued less among the gatekeepers.

Overall, the findings suggest that the traditional picture of gatekeeping as an instance of wielding expert power is changing. This is particularly due to opportunities offered by the forums social media such as Twitter enabling information seekers to become gatekeepers within their specialised knowledge domain (Pearson and Kosicki, 2017). However, as Metzger (2007, p. 2079) has pointed out, the flipside of this development is that information posted on the web may not be subject to filtering through professional gatekeepers, resulting in the lack of traditional authority indicators such as author identity or established reputation. This means that the Internet has made the need to critically evaluate information more important than ever before while also shifting the burden of credibility assessment and quality control from professional gatekeepers onto individual information seekers. In a similar vein, the Network Gatekeeping Theory developed by Barzilai-Nahon (2008) proposes that individual and stable gatekeepers have been largely replaced by a network of people who may act both in the roles of gatekeepers and gated.

Developments such as these emphasize the need to rethink the construct of gatekeeping, as well as to reconsider the nature of expert power constitutive of it. However, it is premature to predict that the concepts of gatekeeping and gatekeepers would become needless in the future. Rather, it is evident that gatekeeping is in transition. As aptly pointed out by Heinderyckx and Vos (2016, p. 31 ), if the concept of gatekeeping accounts for how information circulates or does not circulate and 
why all information is not equally available to all persons, then it should be clear that gatekeeping addresses phenomena that still very much exist.

\section{Conclusion}

The findings of the present study provide further support for Introna's (1999) assumption that power is a factor with great potential to explain the complexities of information behaviour. The findings suggest that the construct of gatekeeping can be elaborated further by examining how expert power figures in the characterizations of gatekeepers, and how power of this type is trusted or challenged among information seekers and receivers. The findings highlight that the gatekeepers' expert power is primarily based on the assumption that certain individuals in an organization or societal group have superior knowledge and skills valuable to other people, coupled with an ability to control or facilitate access to information. The power relationships between the gatekeepers and those subject to gatekeeping tend to vary contextually, depending on the extent to which the gated have access to alternative sources of information. The findings also highlight the need to elaborate the construct of gatekeeping by examining its nature in the networked information environments where the traditional picture of gatekeepers controlling or facilitating access to information sources is eroding.

As the present investigation is just one of the first steps to thematize power as a contextual factor of information behaviour from the viewpoint French and Raven's (1959) classic typology, additional research is required to elaborate the ways in which power of various types figures in information seeking and sharing. To achieve this, the nature of social power should be examined from alternative theoretical frameworks. In this regard, the Foucauldian approach to power holds good promises, as demonstrated by the studies of Olsson (2007) and Heizmann and Olsson (2007). Moreover, one of the issues deserving further attention deals with the nature of social power inherent in cognitive authority (author anonymized, 2019) and opinion leadership (Katz and Lazarsfeld, 1955) - two constructs closely related to gatekeeping. In the forums of social media, for example, the same individual may be recognized as a cognitive authority due to his or her perceived trustworthiness and competence in a specific domain (Doty, 2015), an active gatekeeper forwarding information filtered from mass media sources (Xu and Feng, 2014), as well as an opinion leader influencing people's views (Park, 2013). By taking a comparative view, the examination of similarities and differences in the manifestations of social power may refine the picture of how power of this type is constitutive of gatekeeping, opinion leadership and cognitive authority. Findings of studies such as these would also shed further light upon why information sources are trusted and challenged among people sharing and seeking information.

\section{References}

Agada, J. (1999), "Inner-city gatekeepers: an exploratory survey of their information use environment", Journal of the American Society for Information Science, Vol. 50 No. 1, pp. 74-85.

Allen, T.J. (1966), "Performance of communication channels in the transfer of technology", Industrial Management Review, Vol. 8 No. 1, pp. 87-98.

Allen, T.J. (1977), Managing the Flow of Technology. Technology Transfer and the Dissemination of Technological Information within the $R \&$ D Organization, MIT Press, Cambridge, MA.

Author anonymized (2019), "Cognitive authority as an instance of informational and expert power", Manuscript submitted for review in Aslib Journal of Information Management (December 2019). 
Barzilai-Nahon, K. (2008), "Toward a theory of network gatekeeping: a framework for exploring information control", Journal of the American Society for Information Science and Technology, Vol. 59 No. 9, pp. 1493-1512.

Barzilai-Nahon, K. (2009), "Gatekeeping: a critical review”, in Cronin, B. (Ed.), Annual Review of Information Science and Technology, Vol. 43, Wiley, Medford, NJ, pp. 1-79.

Bastos, M.T., Raimundo, R.L.G. and Travitzki, R. (2013), "Gatekeeping Twitter: message diffusion in political hashtags”, Media, Culture \& Society, Vol. 35 No. 2, pp. 260-270.

Castells, M. (1997), The Power of Identity. The Information Age: Economy, Society and Culture, Blackwell, Oxford, U.K.

Chakraborty, A., Ghosh, S., \& Ganguly, N. and Gummadi, K.P. (2019), "Editorial versus audience gatekeeping: analyzing news selection and consumption dynamics in online news media", IEEE Transactions on Computational Social Systems, Vol. 6 No. 4, pp. 680-691.

Chu, C.M. (1999), "Immigrant child mediators (ICM): bridging the literacy gap in immigrant communities", The New Review of Children's Literature and Librarianship, Vol. 5, No. 1, pp. 85-94.

Clegg, S.R. (1989), Frameworks of Power, Sage, London, UK.

Corra, M. and Willer, D. (2002), “The gatekeeper”, Sociological Theory, Vol. 20 No. 2, pp. 180-207.

Cummings, A.R. (2017), The Effects of Social Power Bases within Varying Organizational Cultures, City University of New York, New York, NY (PhD thesis), available at: https://academicworks.cuny.edu/cgi/viewcontent.cgi?article=3351\&context=gc_etds (accessed 17 March 2020).

Donohue, G.A., Tichenor, P.J, and Olien, C.N. (1972), Gatekeeping: Mass Media Systems and Information Control, Sage, Beverly Hills, CA.

Doty, C. (2015), "Social epistemology and cognitive authority in online comments about vaccine safety", in iConference 2015 Proceedings, Newport Beach, CA, March 24-27, 2015, available at: http://hdl.handle.net/2142/73664 (accessed 13 January 2020).

Elias, S. (2008), "Fifty years of influence in the workplace. The evolution of the French and Raven power taxonomy”, Journal of Management History, Vol. 14 No.3, pp. 267-283.

Erchul, W.P. and Raven, B.H. (1997), "Social power in school consultation: a contemporary view of French and Raven's bases of power model”, Journal of School Psychology, Vol. 35 No. 2, pp. 137171.

Eysenbach, G. (2007), "From intermediation to disintermediation and apomediation: new models for consumers to access and assess the credibility of health information in the age of Web 2.0", Studies in Health Technology and Informatics, Vol. 129, pp. 162-166.

Eysenbach, G. (2008), "Credibility of health information and digital media: new perspectives and implications for youth", in Metzger, M. and Flanagin, A, (Eds), Digital Media, Youth, and Credibility, The MIT Press, Cambridge, MA, pp. 123-154. 
Fisher, K.E., Marcoux, E., Miller, L.S., Sánchez, A. and Ramirez Cunningham, E. (2004), "Information behaviour of migrant Hispanic farm workers and their families in the Pacific Northwest", Information Research, Vol. 10 No, 1, available at: http://InformationR.net/ir/101/paper199.html (accessed 13 January 2020).

Foucault, M. (1998), The History of Sexuality. Vol. 1: An Introduction, Penguin, London, UK.

Foucault, M. (1991), Discipline and Punish: The Birth of a Prison, Penguin, London, UK.

French, J.R.P. and Raven, B. (1959), "The bases of social power", in Cartwright, D. (Ed.), Studies in Social Power, University of Michigan Press, Ann Arbor, MI, pp. 259-269.

Furner, J. (2004), "Conceptual analysis: a method for understanding information as evidence, and evidence as information", Archival Science, Vol. 4 No. 3-4, pp. 233-265.

Haas, A. (2015), "Crowding at the frontier: boundary spanners, gatekeepers and knowledge brokers", Journal of Knowledge Management, Vol. 19 No. 5, pp. 1029-1047.

Haugaard, M. and Clegg, S.R. (2009), "Introduction: why power is the central concept of the social sciences", in Clegg, S.R. and Haugaard, M. (Eds), The Sage Handbook of Power, Sage, London, UK, pp. 1-24.

Heinderyckx, F. (2015), "Gatekeeping redux", in Vos, T.P. and Heinderyckx, F. (Eds), Gatekeeping in Transition, Routledge, New York, NY, pp. 253-267.

Heinderyckx, F. and Vos, T.B. (2016), "Reformed gatekeeping", CM: Communication and Media, Vol. 11, pp. 29-46.

Heizmann, H. and Olsson, M.R. (2015), "Power matters: the importance of Foucault's power/knowledge as a conceptual lens in KM research and practice", Journal of Knowledge Management, Vol. 19 No. 4, pp. 756-769.

Hirokawa, R.Y. and Lowe, J.B. (2002), "Katz and Lazarsfeld revisited: using intermedia theory to enhance health campaigns", paper presented at the Global Health Conference, University of Iowa, Iowa, 19-21 April, 2002, available at: https://www.infoamerica.org/documentos_pdf/eliu_katz2.pdf (accessed 13 January 2020).

Hirvonen, N., Tirroniemi, A. and Kortelainen, T. (2019), "The cognitive authority of user-generated health information in an online forum for girls and young women", Journal of Documentation, Vol. 75 No. 1 , pp. $78-98$.

Holmes, J. (2007), "Monitoring organisational boundaries: diverse discourse strategies used in gatekeeping", Journal of Pragmatics, Vol. 39 No. 11, pp. 1993-2016.

Introna, L.D. (1999), "Context, power, bodies and information: exploring the 'entangled' contexts of information", in Wilson, T.D. and Allen, D.K. (Eds), Exploring the Contexts of Information Behaviour. Proceedings of the 2nd International Conference on Research in Information Needs, Seeking and Use in Different Contexts, 13-15 August 1998, Sheffield, Graham Taylor, London, UK, pp. 1-9. 
Jucquois-Delpierre, M. (2007), "Fictional reality or real fiction: how can one decide? The strengths and weaknesses of information science concepts and methods in the media world", Journal of Information, Communication and Ethics in Society, Vol. 5 Nos. 2-3, pp. 235-252.

Katz, E. and Lazarsfeld, P.F. (1955), Personal Influence: The Part Played by People in the Flow of Mass Communication, Free Press, Glencoe, IL.

Katz, R. and Tushman, M. (1979), "Communication patterns, project performance, and task characteristics", Organizational Behavior and Human Performance, Vol. 23 No. 2, pp. 139-162.

Laidlaw, E.B. (2010), “A framework for identifying Internet information gatekeepers”, International Review of Law, Computers \& Technology, Vol. 24 No. 3, pp. 263-276.

Lewin, K. (1943), "Forces behind food habits and methods of change", Bulletin of the National Research Council, Vol. 108, pp. 35-65.

Lewin, K. (1951), Field Theory in Social Science: Selected Theoretical Papers, D. Cartwright (Ed.), Harper \& Row, New York: NY.

Lu, Y. (2007), "The human in human information acquisition: understanding gatekeeping and proposing new directions in scholarship", Library \& Information Science Research, Vol. 29 No. 1, pp. 103-123.

Lukes, S. (1974), Power: A Radical View, Macmillan, London, UK.

Metoyer-Duran, C. (1991), "Information-seeking behavior of gatekeepers in ethnolinguistic communities: overview of taxonomy", Library \& Information Science Research, Vol. 13 No. 4, pp. 319-346.

Metoyer-Duran, C. (1993), "Information gatekeepers", in Williams, M. (Ed.), Annual Review of Information Science and Technology, Vol. 28, Learned Information Inc., Medford, N.J. pp. 111-150.

Metzger, M.J. (2007), "Making sense of credibility on the web: models for evaluating online information and recommendations for future research", Journal of the American Society for Information Science and Technology, Vol. 58 No. 3, pp. 2078-2091.

Mutsheva, A. (2007), "A theoretical exploration of information behaviour: a power perspective", Aslib Proceedings, Vol. 59 No. 3, pp. 249-263.

Mutsheva, A. (2010), "The use of information by environmental planners: a qualitative study using grounded theory methodology”, Information Processing \& Management, Vol. 46 No. 2, pp. 212-232.

Ojennus, P. (2020), "Modelling advances in gatekeeping theory for academic libraries", Journal of Documentation, Vol. 76 No 2, pp. 389-408.

Olsson, M. (2007), "Power/knowledge: the discursive construction of an author", Library Quarterly, Vol. 77 No. 2, pp. 219-240. 
Olsson, M. and Heizmann, H. (2015), "Power matters: Foucault's pouvoir/savoir as a conceptual lens in information research and practice", Information Research, Vol. 20 No. 4, available at: http://InformationR.net/ir/20-4/paper695.html (accessed 13 January 2020).

Park, C.S. (2013), "Does Twitter motivate involvement in politics? Tweeting, opinion leadership, and political engagement”, Computers in Human Behavior, Vol. 29 No. 4, pp. 1641-1648.

Pearson, G.D.H. and Kosicki, G.M. (2017), "How way-finding is challenging gatekeeping in the digital age", Journalism Studies, Vol. 18 No. 9, pp. 1087-1105.

Petruzzelli, A.M. (2008), "Proximity and knowledge gatekeepers: the case of the Polytechnic University of Turin”, Journal of Knowledge Management, Vol. 12 No. 5, pp. 34-51.

Pingree, R.J. and Stoycheff, E. (2013), "Differentiating cueing from reasoning in agenda-setting effects, Journal of Communication, Vol. 63, No. 5, pp. 852-872.

Raven, B.H. (2008), "The bases of power and the power/interaction model of interpersonal influence", Analyses of Social Issues and Public Policy, Vol. 8 No. 1, pp. 1-22.

Rieh, S.Y. (2002), "Judgment of information quality and cognitive authority in the Web", Journal of the American Society for Information Science and Technology, Vol. 53 No. 2, pp. 145-161.

Schultze, U. and Boland, RJ. (2000), "Knowledge management technology and the reproduction of knowledge work practices", Journal of Strategic Information Systems, Vol. 9, Nos. 2-3, pp. 193-212.

Shoemaker, P. (1991), Gatekeeping, Sage, Newbury Park, CA.

Shoemaker, P.J. and Vos, T.P. (2009), Gatekeeping Theory, Routledge, New York, NY.

Soroka, S.N. (2012), "The gatekeeping function: distributions of information in media and the real world”, The Journal of Politics, Vol. 74, No. 2, pp. 514-528

Sturges, P. (2001), "Gatekeepers and other intermediaries", Aslib Proceedings, Vol. 53 No. 2, pp. 6267.

Tushman, M.L. and Katz, R. (1980), "External communication and project performance: an investigation into the role of gatekeepers", Management Science, Vol. 26 No. 11, pp. 1071-1085.

Urban, J. and Schweiger, W. (2014), "News quality from the recipients' perspective. Investigating recipients' ability to judge the normative quality of news", Journalism Studies, Vol. 15 No. 6, pp. 821-840.

Vos, T.P. (2015), "Revisiting gatekeeping theory during a time of transition", in Vos, T.P. and Heinderyckx, F. (Eds), Gatekeeping in Transition, Routledge, New York, NY, pp. 3-24.

Walsh, J.N. (2015), "Developing new categories of knowledge acquisition, translation and dissemination by technological gatekeepers", International Journal of Information Management, Vol. 35 No. 5, pp. 594-605. 
Weber, M. (1978), Economy and Society. An Outline of Interpretative Sociology, University of California Press, Berkeley, CA.

White, D.M. (1950), “The 'gate keeper': a case study in the selection of news", Journalism Quarterly, Vol. 27 No. 4, pp. 383-390.

Wilson, P. (1983), Second-Hand Knowledge: An Inquiry into Cognitive Authority, Greenwood Press, Westport, CT.

Wu S., Hofman J.M., Mason W.A. and Watts, D.J. (2011), "Who says what to whom on Twitter", in Proceedings of the 20th ACM International World Wide Web Conference, Hyderabad, India, 28 March - 1 April, 2011 (pp. 705-714), available at: http://www.wwwconference.org/proceedings/www2011/proceedings/p705.pdf (accessed 13 January 2020).

$\mathrm{Xu}$, W.W. and Feng, M. (2014), "Talking to the broadcasters on Twitter: networked gatekeeping in Twitter conversations with journalists", Journal of Broadcasting \& Electronic Media, Vol. 58 No. 3, pp. 420-437.

Yoo, S. and Park, J-H. (2018), "Hybrid gatekeeping framework for value-added information services", Library \& Information Science Research, Vol. 40 No. 1, pp. 61-72. 